\title{
Discussion of Glasser's “Quality World” among Medical Students Benefited Group Dynamics
}

\author{
Se Ho Hwang ${ }^{1,2}$, Fan Huan ${ }^{3}$ and Kun Hwang ${ }^{3}$ \\ 1. Leicester Medical School, Leicester LE1 7RH, UK \\ 2. Inha Research Institute for Medical Science, Inha University, Incheon 402-751, Republic of Korea \\ 3. Department of Plastic Surgery, Inha University School of Medicine, Incheon 400-711, Republic of Korea
}

\begin{abstract}
Purpose: The aim of this study is to analyze the Glasser's "Quality World" as it is discussed among the medical students and to see if there is any relationship between it and their academic/creativity scores. It also seeks if this discussion is of any benefit to the group dynamics. Methods: Participants were 205 medical students, 4 to 7 students were allocated as a group. They were asked to fill an open answer to 4 categories of "Quality World" (the people we most want to be with, the things we most want to own or experience, the idea or system of belief that govern much of our behavior, and the places we most want to visit or live) and discuss them in an open forum. Torrance Tests of Creative Thinking were performed to the students. They answered the Likert scale question whether discussing the "Quality World" with peers benefited the group dynamics or not. Results: Among 205 students, 50.2\% wanted to be with adoring people; followed by entertainers and artists (18\%), $51.7 \%$ wanted to own material wealth; spiritual values were second in importance (21\%), 27.3\% considered family, friends, and lovers most valuable; followed by happiness (21\%), 52.2\% wished for an overseas trip; trip to the mountains, seas, or deserts was next in importance (14.1\%). Most of the respondents answered that discussing "Quality World" benefited their group dynamics. Conclusion: We suggest that discussing Glasser's "Quality World" might be a useful tool to gain understanding among the health personnel in small group activities and increase group dynamics.
\end{abstract}

Key words: Behavior, creativeness, health personnel, personality, students, medical.

\section{Introduction}

American psychiatrist, William Glasser, wrote a book based on his experience. He suggests that we all choose how to behave at any given time, and we can not control anyone's behavior but our own. He called this Choice Theory. His Choice Theory suggests the existence of a "Quality World". The phrase "Quality World" represents a person's total outlook and understanding of the world around them as it relates to people, possessions, beliefs, etc.. Dr. Glasser describes the "Quality World" as a "personal picture album" of all the people, things, ideas, and ideals that we have discovered and it increases the quality of our lives [1].

We thought discussing "Quality World" in small group session at the beginning of their clerkship might benefit their group dynamics because they will

Corresponding author: Kun Hwang, M.D., Ph.D., research field: medical education. E-mail: jokerhg@inha.ac.kr. understand better about their peers. We also wanted to know what types of "Quality World" medical students wish to have and their relationship to academic marks or creativity scores.

The aim of this study is to analyze the Glasser's "Quality World" as it is discussed among the medical students and to see if there is any relationship between it and their academic/creativity scores. It also seeks to see if this "Quality World" discussion is of any benefit to the group dynamics.

\section{Participants and Procedures}

The participants were medical students in junior class (5th year of 6 year course) from 2002 to 2009. There were 205 participants, 153 men and 52 women, 25 to 36 per year. The mean overall age was $25.8 \pm 2.6$ years. In two weeks of Plastic Surgery clerkship, 4 to 7 students were allocated as a group. 
At the beginning of their clerkship, they were asked to fill an open answer to "Quality World" and explain the reason behind it within about 30 minutes and discuss them in open forum. "Quality world" fall into four categories: (1) the people we most want to be with; (2) the things we most want to own or experience; (3) the idea or system of belief that govern much of our behavior; (4) the places we most want to visit or live.

At the end of their clerkship, they were asked to answer yes or no to the questionnaire composed of 40 items of creativity based on TTCT (Torrance Tests of Creative Thinking) - Verbal, which was modified and translated in Korean [2]. They were also asked to respond to the Likert scale question whether discussing the "Quality World" with peers benefited the group dynamics or not.

\section{Results}

All the 205 students of clerkship participated in the discussion and answered the questionnaires. Their academic marks were obtained after completion of their senior year.

\subsection{The People We Most Want to be With}

Among the 205 participants, 103 students (50.2\%) wanted to be with adoring people, followed by entertainers and artists (37 [18\%]), scholars (24 [12\%]), powerful men (22 [11\%]), clerics (4 [2\%]). Adoring people (103) consisted of friends (54 [52.4\%]), family (27 [26.2\%]), teachers (13 [12.6\%]), and himself of the past and the future (5 [4.8\%]; Fig. 1).

The creativity scores of the students who wanted to be with scholars, powerful men, or clerics (Group 1), adoring people (Group 2), and entertainer or artists (Group 3) was $25.14 \pm 4.60,24.22 \pm 3.87$, and $23.67 \pm$ 3.98 , respectively. There was no significant difference between the 3 groups $(P=0.275$ [ $t$-test]; Table 1$)$.

The academic marks of the students of Group 1 and Group 3 were $68.90 \pm 9.98$ and $66.05 \pm 9.08$, respectively. There was no significant difference between Grpup 1 and Group $3(P=0.171[t$-test $]$; Table 2).

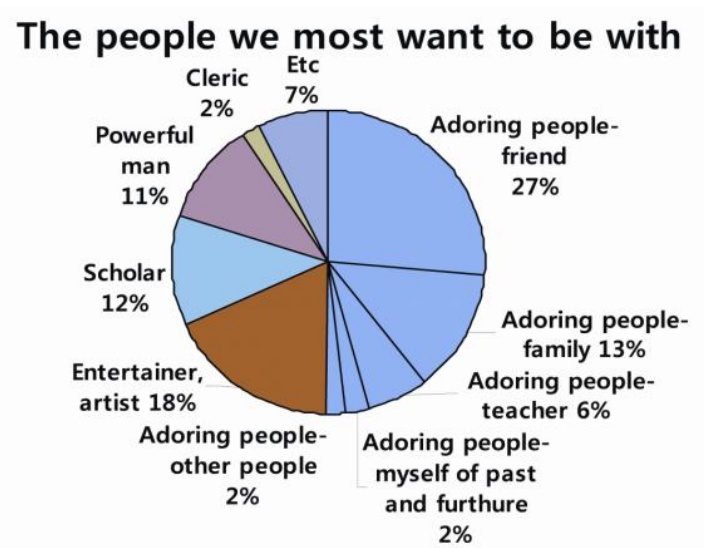

Fig. 1 The people we most want to be with.

Table 1 Creativity scores according to the people we most want to be with.

\begin{tabular}{llll}
\hline & Mean & SD & $\mathrm{F}(P)$ \\
\hline Entertainers, artists & 23.67 & 3.98 & \\
Scholars, powerful men, clerics & 25.14 & 4.60 & $1.300(0.275)$ \\
Adoring people & 24.22 & 3.87 & \\
\hline
\end{tabular}

Table 2 Comparison of academic marks according to the people we most want to be with.

\begin{tabular}{llll}
\hline & Mean & SD & $\mathrm{F}(P)$ \\
\hline Entertainers, artists & 66.05 & 9.08 & \multirow{2}{*}{$1.192(0.171)$} \\
Scholars, powerful men, clerics & 68.90 & 9.98 & \\
\hline
\end{tabular}

\subsection{The Things We Most Want to Own or Experience}

Among the 205 participants, 106 students (51.7\%) wanted to own material wealth, followed by spiritual values (43 [21\%]), power (32 [15.6\%]), honor (11 [5.4\%]), and health (9 [4.4\%]). Material wealth (106) consisted of a home or car (63 [59.5\%]), a computer or camera (35 [33\%]), and money (8 [7.5\%]). Spiritual value (43) consisted of self-confidence or courage (16 [37.2\%]), freedom or time (15 [34.9\%]), and love or a lover (12 [27.9\%]; Fig. 2).

There was no significant difference in the creativity scores $(P=0.888)$ and academic marks $(P=0.849)$ between the groups (Tables 3 and 4).

\subsection{The Idea or System of Beliefs that Governs Much of Our Behavior}

Among the 205 participants, 57 students (27.3\%) considered family, friends, and lovers most valuable, followed by happiness (44 [21\%]), human relationships 


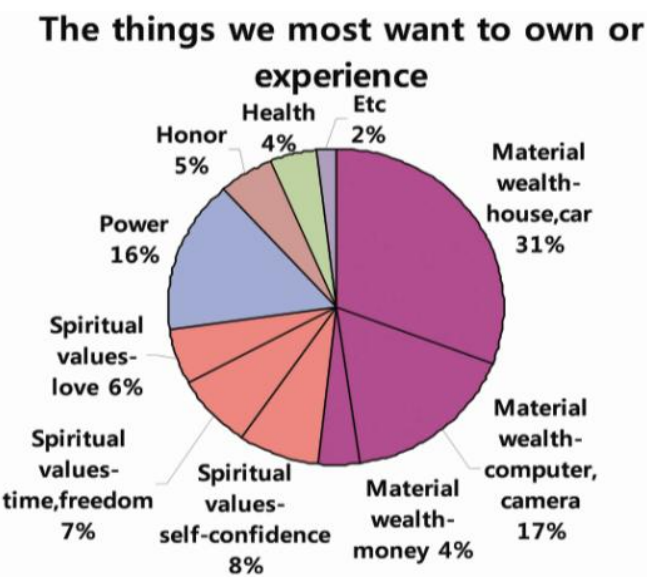

Fig. 2 The things we most want to own or experience.

Table 3 Creativity scores according to the things we most want to own.

\begin{tabular}{llll}
\hline & Mean & SD & $\mathrm{F}(P)$ \\
\hline Material wealth & 24.05 & 4.11 & \\
Spiritual values & 24.53 & 3.79 & \\
Power & 24.78 & 4.06 & $0.340(0.888)$ \\
Honor & 25.03 & 4.93 & \\
Health & 24.88 & 3.52 & \\
\hline
\end{tabular}

Table 4 Academic marks according to the things we most want to own.

\begin{tabular}{llll}
\hline & Mean & SD & $\mathrm{F}(P)$ \\
\hline Material wealth & 66.99 & 9.97 & \\
Spiritual values & 67.52 & 10.53 & \\
Power & 64.21 & 8.41 & 0.342 \\
Honor & 68.45 & 9.66 & $(0.849)$ \\
Health & 67.21 & 11.52 & \\
\hline
\end{tabular}

(33 [16.1\%]), love (18 [8.8\%]), quality of life (12 [5.9\%]), knowledge (19 [4.9\%]), and freedom (7 [3.4\%]). Only $2(1.0 \%)$ students considered wealth to be most valuable. Another 2 students (1.0\%) responded that honor is most valuable (Fig. 3).

The academic marks of the students who thought wealth, honor, and human relationships are most valuable $(64.36 \pm 10.26)$ was minimally lower than the students who thought family, friends, lovers, happiness, love, quality of life, and freedom are most valuable $(68.10 \pm 9.90)$; however, it was not statistically significant $(P=0.050$ [ $t$-test $]$; Table 5$)$.

The creativity scores of the students who thought wealth, honor, and human relationships are most valuable were $25.06 \pm 4.46$. The creativity scores of the students who thought family, friends, lovers, happiness, love, quality of life, and freedom are most valuable was $24.37 \pm 4.08$. The creativity scores of the students who thought knowledge is most valuable was $23.67 \pm$ 3.98; however, there was no significant difference between the two groups $(P=0.091[t$-test $])$.

\subsection{The Places We Most Want to Visit or Live}

Among the 205 participants, 107 students (52.2\%) wished for an overseas trip, followed by the mountains, seas, or deserts (29 [14.1\%]). A domestic trip (25 [12.2\%]), sports game or match (17 [8.3\%]), and space trip or uninhabited island exploration (5 [2.4\%]) followed (Fig. 4).

The academic marks of the students who wished for a trip to the mountains, seas, or deserts $(70.41 \pm 10.64)$ were higher than the students who wished for an overseas or domestic trip $(67.02 \pm 10.20 ; P=0.127$ [t-test $])$ and significantly higher than the students who wished for a space trip or uninhabited island exploration $(64.01 \pm 7.63 ; P=0.013[t$-test $]$; Tables 6 and 7).

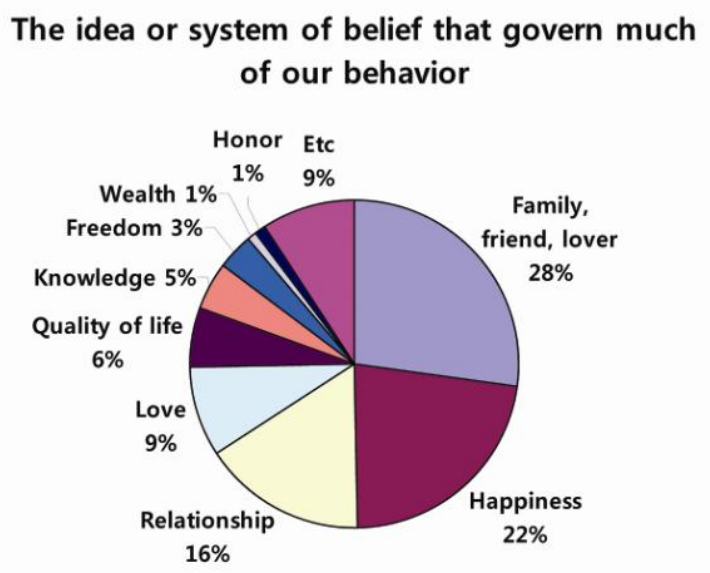

Fig. 3 The idea or system of belief that govern much of our behavior.

Table 5 Comparison of academic marks according to the idea or system of belief that governs much of our behavior.

\begin{tabular}{llll}
\hline & Mean & SD & $\mathrm{F}(P)$ \\
\hline $\begin{array}{l}\text { Wealth, honor, human } \\
\text { relationships }\end{array}$ & 64.36 & 10.26 & 0.053 \\
$\begin{array}{l}\text { Family, friends, lovers, happiness, } \\
\text { love, quality of life, freedom }\end{array}$ & 68.10 & 9.90 & $(0.050)$ \\
\hline
\end{tabular}




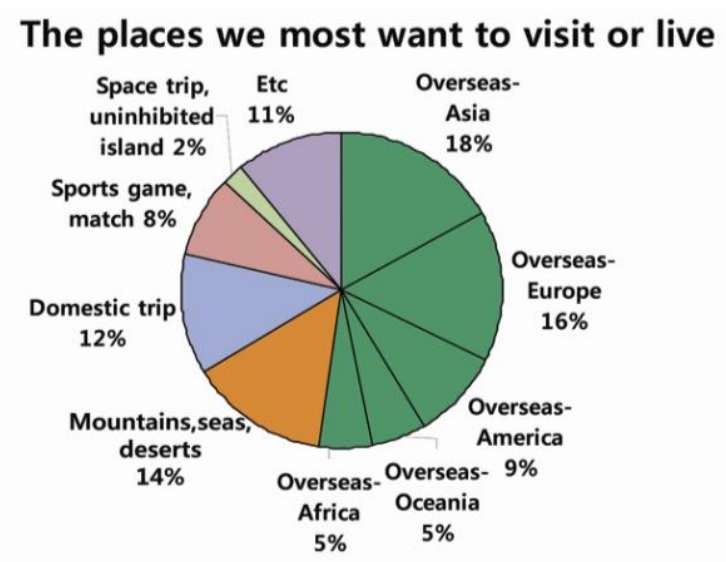

Fig. 4 The places we most want to visit or live.

Table 6 Academic marks according to the places we most want to visit.

\begin{tabular}{llr}
\hline & Mean & \multicolumn{1}{c}{ SD } \\
\hline Overseas trip, domestic trip & 67.02 & 10.20 \\
Mountains, sea, desert & 70.41 & 10.64 \\
Sports game, match & 69.73 & 9.29 \\
Space trip, uninhabited island & 64.01 & 7.63 \\
\hline
\end{tabular}

Table 7 Comparison of academic marks according to the places we most want to visit or live of the students who thought the places they most want to.

\begin{tabular}{llll}
\hline & Mean & SD & F $(P)$ \\
\hline Mountains, sea, desert & 70.41 & 10.64 & \\
$\begin{array}{l}\text { Space trip, uninhabited } \\
\text { island }\end{array}$ & 64.01 & 7.63 & $5.008(0.013)$ \\
\hline
\end{tabular}

Table 8 Creativity scores according to the places we most want to visit.

\begin{tabular}{lll}
\hline & Mean & SD \\
\hline Overseas trip, domestic trip & 23.92 & 4.11 \\
Mountains, sea, desert & 25.74 & 4.66 \\
Sports game, match & 23.27 & 4.04 \\
Space trip, uninhabited & 25.48 & 3.28 \\
island & & \\
\hline
\end{tabular}

Table 9 Comparison of creativity scores according to the places the authors most want to visit.

\begin{tabular}{llll}
\hline & Mean & SD & $\mathrm{F}(P)$ \\
\hline Overseas trip, domestic trip & 23.92 & 4.11 & \\
$\begin{array}{l}\text { Space trip, uninhabited } \\
\text { island }\end{array}$ & 25.48 & 3.28 & $3.157(0.049)$ \\
\hline
\end{tabular}

The creativity scores of the students who wished for a space trip or uninhabited island exploration (25.48 \pm $3.28)$ were significantly higher than the students who wished for an overseas or domestic trip (23.92 \pm 4.11 ; $P=0.049$ [t-test $]$; Tables 8 and 9).

\subsection{Influence of Presenting "Quality World" to the Group Dynamics.}

Most of the respondent answered that discussing "Quality World" benefited their group dynamics. (strongly disagree: 0 ; disagree: 0 ; neither agree nor disagree: 4; agree 137; strongly agree: 64). Through this they had better understanding of their peers.

\section{Discussion}

Quality world, a small personal world, which each person starts to create in his or her memory shortly after birth and continues to create and re-create throughout life, is made up of specific pictures that portray, more than anything else we know, the best ways to satisfy one or more of our basic needs [3]. Quality world pictures internally create notions of how we would like things to be, and are related to certain basic needs of every human being.

What these pictures portray falls into the following four categories: (1) the people we most want to be with; (2) the things we most want to own or experience; (3) the idea or system of beliefs that govern much of our behavior; and (4) the places we most want to visit or live. Anytime we feel very good, we are choosing to behave so that someone or something with some belief in the real world has come to match a picture of that person, thing, or belief in our quality world [1].

It is interesting that among the 205 participants in the current study, 106 students $(51.7 \%)$ desired to own material wealth; however, only $2(1.0 \%)$ students answered wealth as being most valuable. Another 2 students $(1.0 \%)$ stated that honor is most valuable. Eleven students (5.4\%) students wanted to have honor; however, only 2 students $(1.0 \%)$ considered honor most valuable. As a belief that governs much of their behavior, only a small portion of medical students thought wealth or honor are most valuable. Despite their low estimated value, wealth or honor are most important to pursue.

The academic marks of the students who wanted to be with scholars, powerful men, or clerics $(68.90 \pm 9.98)$ 
were minimally higher than the students who wanted to be with entertainers or artists $(66.05 \pm 9.08)$. However, there was no statistically significant difference between the two groups of students $(P=0.171[t$-test $])$.

The academic marks of the students who wished for a trip to the mountains, sea, or desert $(70.22 \pm 10.68)$ was higher than the students who wished for an overseas or domestic trip $(67.25 \pm 10.11 ; P=0.083$ [t-test]) and significantly higher than the students who wished for a space trip or uninhabited island exploration $(64.19 \pm 7.71 ; P=0.018[t$-test $])$. The creativity scores of the students who wished for a space trip or uninhabited island exploration $(25.48 \pm 3.28)$ was significantly higher than the students who wished for an overseas or domestic trip $(23.92 \pm 4.11 ; P=$ 0.049 [ $t$-test $])$. The results show that the students who have higher creativity scores tend to have a space trip or uninhabited island exploration; however, relatively lower academic marks.

In the beginning of the clerkship, the students do not know their peers well. Discussing the "Quality World" in the small group could help to understand their group members since their "personal photo album" in their mind is exposed. Most of the respondents answered that discussing "Quality World" benefited their group dynamics. Through this discussion they had better understanding of their peers.

We suggest that discussing Glasser's "Quality World" might be a useful tool to gain understanding among the health personnel in small group activities and increase group dynamics.

\section{Acknowledgment}

The authors would like to acknowledge the help of Ae Sun Park, Ph.D., for her help in reference search. We are grateful to Dr Sowhey Park, M.D., for reviewing this manuscript. This study was supported by grant from Inha University (INHA-Research Grant).

\section{References}

[1] W. Glasser, Choice Theory: A New Psychology of Personal Freedom, HarperCollins Publishers, Inc., New York, 1998.

[2] E.P. Torrance, Guiding Creative Talent, Prentice Hall Press, Englewood Cliffs, 1962.

[3] W. Glasser, L.M. Zunin, Reality therapy, Curr. Psychiatr Ther. 12 (1972) 58-61. 